\title{
Catalytically Assisted Self-Propagating High-Temperature Synthesis of Tantalum Carbide Powders
}

\author{
Troy Kim and Margaret S. Wooldridge \\ Department of Mechanical Engineering, University of Michigan, Ann Arbor, Michigan 48109-2125
}

\begin{abstract}
The use of gas-phase iodine and carbon dioxide as transport agents in the tantalum/carbon/tantalum carbide combustion synthesis system has been examined to determine the effects of transport agents on product composition and microstructure. Two tantalum reactant particle sizes, a range of transport agent concentrations, and total pressures were studied. The effects of the combustion conditions on product morphology and composition were evaluated using scanning electron microscopy, nitrogen adsorption (specific surface area), and $X$-ray diffraction analyses. The results of the investigation indicate that the presence of the iodine vapor and carbon dioxide significantly enhances the combustion synthesis process, leading to higher conversion efficiencies and influencing product microstructure. The results are discussed in the context of gas-phase and solid-phase transport models.
\end{abstract}

\section{Introduction}

$\mathrm{I}_{\mathrm{s} y}^{\mathrm{n}}$ RECENT years, self-propagating high-temperature combustion synthesis (SHS) of materials has gained recognition for its energy efficiency and high-purity products in comparison to other conventional materials synthesis methods. In addition, SHS can be used to rapidly generate materials (grams of product in less than a few seconds) that are otherwise difficult to produce (e.g., transition metal/borides, carbides, and nitrides). ${ }^{1,2}$ Many earlier studies focused on generating near-net shapes, where the product had little physical variation from the reactant geometry. However, volumetric expansion and contraction, and product porosity that are inherent to SHS systems make that a difficult objective to achieve. The current work explores augmenting these aspects of SHS systems as a means to generate high surface area materials, with specific application of the product materials as catalyst powders. Here, the inherent porosity of the SHS product is highly desirable. In particular, the use of gas transport agents in traditional SHS systems is examined with the objective of generating nanostructured powders.

Current areas of interest in SHS research include extending SHS to new materials systems and the development of techniques that can be used to control the microstructure and composition of the product materials. ${ }^{1-3}$ Morphology and composition are critical in designing and optimizing materials for their ultimate end use. Techniques that lead to increased control of these characteristics in SHS systems are key to successful development of SHS technology.

J. J. Petrovic-contributing editor

Manuscript No. 188563. Received May 16, 2000; approved November 13, 2000. Based in part on the thesis submitted by T. Kim for the M.S. degree in mechanical engineering, University of Michigan, Ann Arbor, MI, 2000.

Supported by the Horace H. Rackham School of Graduate Studies at the University of Michigan, and the Office of the Provost at the University of Michigan via the of Michigan, and the Office of the
Career Development Fund Program.
Previous experimental investigations have demonstrated that SHS systems are highly sensitive to the presence of gas-phase species. ${ }^{4,5}$ In fact, it has been proposed that discrepancies between modeling results and experimental data are primarily due to the presence of trace amounts of gas-phase reactants released during combustion. ${ }^{1}$ The gas-phase reactants are created when adsorbed and trapped impurities contained in the powder reactants are released. The gases react with the solid-phase species and assist in the transport of one reactant to another. The gas-phase diffusion transport augments the solid-phase diffusion transport that is required for sustained propagation of the combustion wave. Even small quantities of gas can have a significant impact on SHS combustion, leading to pronounced changes in burning velocity, temperature, product elongation, and reactants-to-products conversion efficiency. ${ }^{1,4,5}$ One important indication of the preliminary studies is that gas-phase transport agents may provide a means to influence and control product microstructure and composition. ${ }^{6,7}$

The presence of gas transport agents is particularly important in systems where the adiabatic flame temperature is below the melting point temperatures of the reactants, products, and intermediate species. It has been proposed that combustion cannot occur in these systems without the presence of gas transport agents. ${ }^{8}$ A solid-phase diffusion model does not support the combustion rates observed in the experimental studies. Mass transport of the reactants by gas-phase intermediates plays a vital role in systems of this type. Essentially, the gas-phase transport agents facilitate the combustion reactions.

Therefore, the primary objective of the current investigation was the systematic evaluation of the effects of gas transport agents on the morphology and composition of SHS-produced materials. In particular, the tantalum/carbon/tantalum carbide $(\mathrm{Ta} / \mathrm{C} / \mathrm{TaC})$ material system

$$
\mathrm{Ta}(s)+\mathrm{C}(s) \rightarrow \mathrm{TaC}(s)
$$

was chosen as the basis for the experimental investigation. The $\mathrm{Ta} / \mathrm{C}$ system was selected as the subject of the current work for several reasons. Tantalum carbide is an industrially significant material because of its high hardness properties; however, transition-metal carbides and nitrides have also been proposed as highly active catalytic materials. ${ }^{9}$ As mentioned above, gasassisted SHS may be an ideal method for generating high surface area catalytic materials. In addition, the $\mathrm{Ta} / \mathrm{C} / \mathrm{TaC}$ system is a nonmelting system $\left(T_{\mathrm{ad}}=2734 \mathrm{~K}\right),{ }^{1}$ which makes $\mathrm{Ta} / \mathrm{C}$ an ideal system for the study of gas-assisted synthesis. Lastly, TaC is a difficult material to make using either conventional techniques or SHS methods. ${ }^{10}$ As a consequence, successful synthesis techniques have high potential for impact on the materials community.

Iodine $\left(\mathrm{I}_{2}\right)$ vapor and carbon dioxide $\left(\mathrm{CO}_{2}\right)$ were chosen as the gas transport agents in the current study. Solid-phase iodine has been shown to be effective in influencing many macroscopic characteristics in $\mathrm{Ta} / \mathrm{C}$ combustion systems (e.g., burning velocity, maximum temperature, etc.). ${ }^{1,4,5} \mathrm{CO}_{2}$ has been proposed as an intermediate formed when trace oxide impurities are present in the reactant powders and carbon is used as one of the reactants. ${ }^{6}$ Therefore, the specific goals of the investigation were to determine 
whether and to what extent the presence of iodine and carbon dioxide vapor affects $\mathrm{TaC}$ product microstructure and composition in SHS-generated materials.

\section{Experimental Procedure}

All experiments were conducted using the combustion chamber shown schematically in Fig. 1. The properties of the reactant materials are listed in Table I. Samples were prepared by mixing the as-received powder reactants in equimolar ratios $(\mathrm{Ta}: \mathrm{C}=1: 1)$ for a minimum of $12 \mathrm{~h}$ using a rolling-pin mixer. The mixtures were then compacted into cylindrical pellets $(1.3 \mathrm{~cm}$ diameter, $2.4-3 \mathrm{~cm}$ length) using a mechanical press $(P=49.16 \mathrm{MPa}$, green densities from $19 \%$ to $34 \%$ ). Two wells ( $1.2 \mathrm{~mm}$ diameter, $5.5 \mathrm{~mm}$ depth) were drilled into each specimen perpendicular to the cylinder axis at a spacing of $\sim 0.76-1.14 \mathrm{~cm}$. Thermocouples were placed in each well to monitor sample temperatures and to determine burning velocities. The upper thermocouple was placed $\sim 0.51-1.27 \mathrm{~cm}$ from the tungsten filament depending on overall specimen length. Burning velocities were determined from the temperature profiles and the known spacing of the thermocouples. The effects of the gas transport additives on the burning velocities are outside the scope of the present work and are discussed in Kim and Wooldridge. ${ }^{11}$

The prepared samples (12.29-20.08 g) were placed in the stainless steel combustion chamber on a specimen pedestal (also stainless steel). A ceramic block was used as a feed-through for the thermocouple wires and provided electrical insulation between the thermocouples and the stainless steel chamber. Two C, D, and/or $\mathrm{G}$ type thermocouples were used to monitor the temperature of the specimen, while one type B thermocouple was used to measure the ambient temperature within the chamber. A resistively heated tungsten filament was used to ignite the sample.

To begin an experiment, a specimen was placed in the chamber on the pedestal. The height of the stand was adjusted such that the top of the specimen was $\sim 1 \mathrm{~mm}$ from the filament. The chamber door was sealed and the combustion chamber was repeatedly evacuated and purged with argon. Once the system was prepared, the chamber was then filled with argon to the desired partial pressure. (A pressure gauge was used to monitor the pressure in the chamber at all times.) For the iodine experiments, iodine was sublimed from crystal powder form and the vapor was directed into the combustion chamber using heated stainless steel tubing.
The iodine vapor was added to the chamber until the desired mole fraction of gas transport agent was achieved. The total pressures in the combustion chamber were varied from $P=0.23$ to 1.29 bar for the iodine experiments. For some high $\mathrm{I}_{2}$ mole fraction conditions, it was necessary to conduct the tests with subatmospheric pressures in the combustion chamber. The mole fraction of iodine vapor in the chamber was determined using the Ar and the $I_{2}$ partial pressures.

For the $\mathrm{CO}_{2}$ experiments, the inert gas source 1 and the iodine shown in Fig. 1 were replaced with a compressed-gas cylinder of $\mathrm{CO}_{2}$. The mole fraction of $\mathrm{CO}_{2}$ in the chamber was determined using the $\mathrm{Ar}$ and the $\mathrm{CO}_{2}$ partial pressures. The total pressures in the combustion chamber were varied from $P=0.23$ to 1.60 bar for the $\mathrm{CO}_{2}$ experiments.

After the desired mixture of gases was obtained in the combustion chamber, the combustion reaction was initiated using the tungsten filament. The filament was deactivated immediately after ignition of the sample occurred. After the SHS reaction was complete, the chamber was purged with argon.

The microstructure of the final product material was examined using scanning electron microscopy (Phillips XL-30 SEM) to image the particles, and nitrogen adsorption to determine the specific surface area (BET, Micrometrics ASAP 2010 Accelerated Surface Area and Porosimetry System). Phase composition of the samples was determined via X-ray diffraction (Scintag Thea/Theta Diffraction System, Model XGen-4000; Rigaku rotating anode $\mathrm{X}$-ray diffractometer).

\section{Results}

The effects of reactant particle size (tantalum particles only), mole fraction of gas transport agent, and pressure on the product composition and microstructure were examined. Table II lists the range of conditions studied for each of these parameters. The initial temperature $\left(T_{\mathrm{i}}\right)$, dilution by the final product, the molar ratio of reactants, and the sample radius $(r)$ are all known to affect SHS combustion characteristics. ${ }^{12,13}$ These parameters were not explored in the current work, and were kept constant at $T_{\mathrm{i}}=$ $299 \mathrm{~K}$, Ta:C molar ratio of 1:1, no dilution with $\mathrm{TaC}$, and $r=$ $0.64 \mathrm{~cm}$ throughout the study. The Ta reactant particle sizes $(1.14$ and $1.88 \mu \mathrm{m})$, listed in Tables I and II, were as per manufacturer specifications. An SEM image of the as-received Ta powder $(1.88 \mu \mathrm{m})$ is shown in Fig. 2. For discussion purposes, the

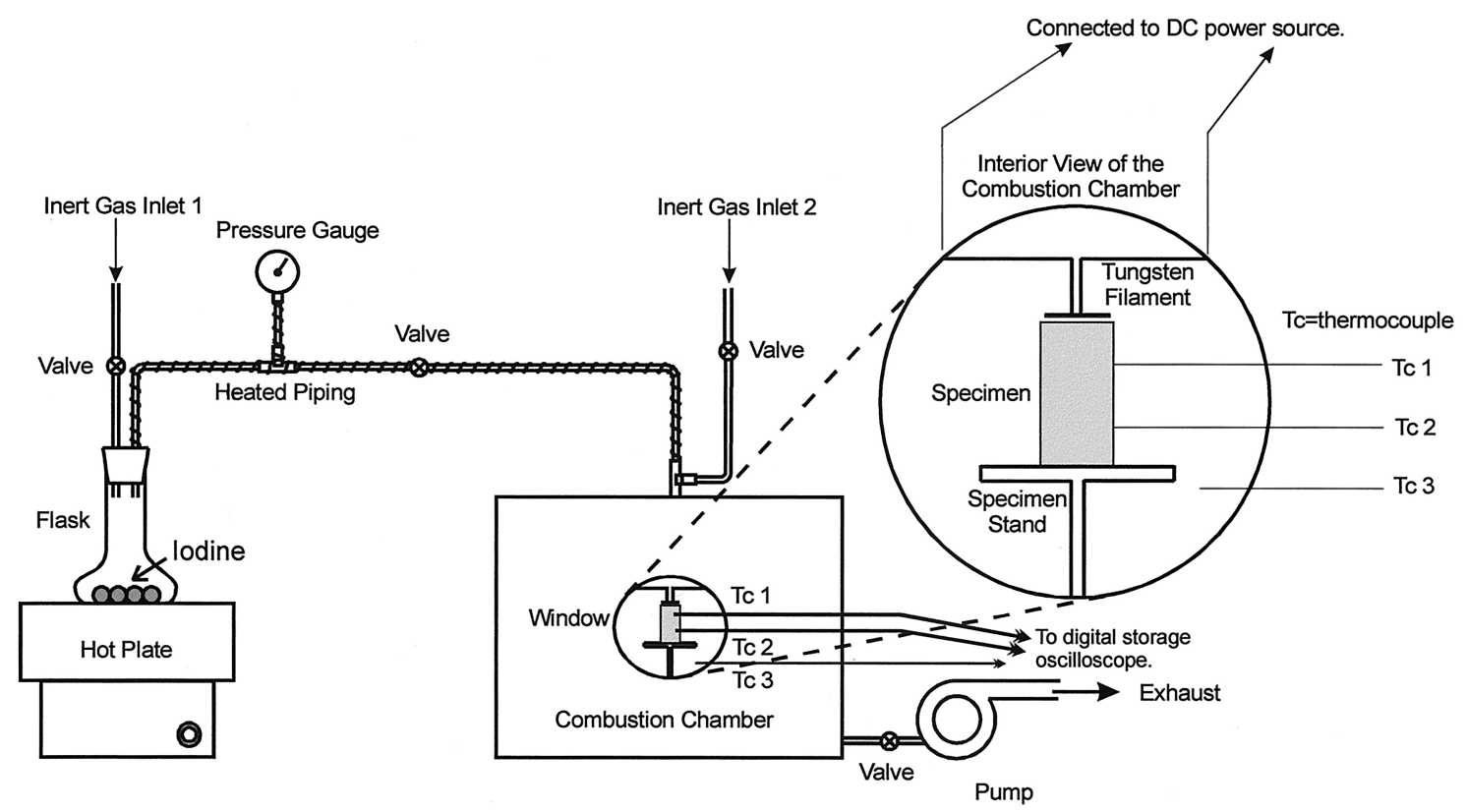

Fig. 1. Experimental schematic of the combustion chamber and gas-handling system. For the carbon dioxide experiments, the iodine source was replaced with a $\mathrm{CO}_{2}$ gas cylinder. 
Table I. Reactant Properties

\begin{tabular}{|c|c|c|c|c|}
\hline Reactant & Manufacturer & Particle size ${ }^{\dagger}$ & Purity $^{\dagger}$ & $\begin{array}{c}\text { Specific surface } \\
\text { area }\left(\mathrm{m}^{2} / \mathrm{g}\right)\end{array}$ \\
\hline Tantalum & Cerac T1000 & $1.88 \mu \mathrm{m}$ & $99.9 \%$ & 0.5868 \\
\hline Tantalum & Cerac T2011 & $1.14 \mu \mathrm{m}$ & $99.9 \%$ & 0.7362 \\
\hline Carbon black & Fisher C198-500 & $44 \mathrm{~nm}$ & $99 \%$ & 28.7855 \\
\hline Carbon dioxide & Linde & N/A & N/A & N/A \\
\hline Iodine & Fisher I35-100 & N/A & $\geq 99.8 \%$ & N/A \\
\hline Argon & Cryogenic & N/A & $99.998 \%$ & N/A \\
\hline
\end{tabular}

${ }^{\dagger}$ As per manufacturer specifications.

Table II. Experimental Conditions Studied in the Current Work

\begin{tabular}{ll}
\hline \multicolumn{1}{c}{ Parameter } & \multicolumn{1}{c}{ Range } \\
\hline Size of tantalum particles ${ }^{\dagger}$ & $1.88 \mu \mathrm{m}, 1.14 \mu \mathrm{m}$ \\
Pressure $\left(\mathrm{CO}_{2}\right.$ experiments) & $0.233-1.60 \mathrm{bar}$ \\
Pressure $\left(\mathrm{I}_{2}\right.$ experiments $)$ & $0.233-1.29 \mathrm{bar}$ \\
Carbon dioxide mole fraction & $40.6-80.0 \%$ \\
Iodine mole fraction & $21.4-57.8 \%$ \\
\hline
\end{tabular}

${ }^{\dagger}$ As per manufacturer specifications.

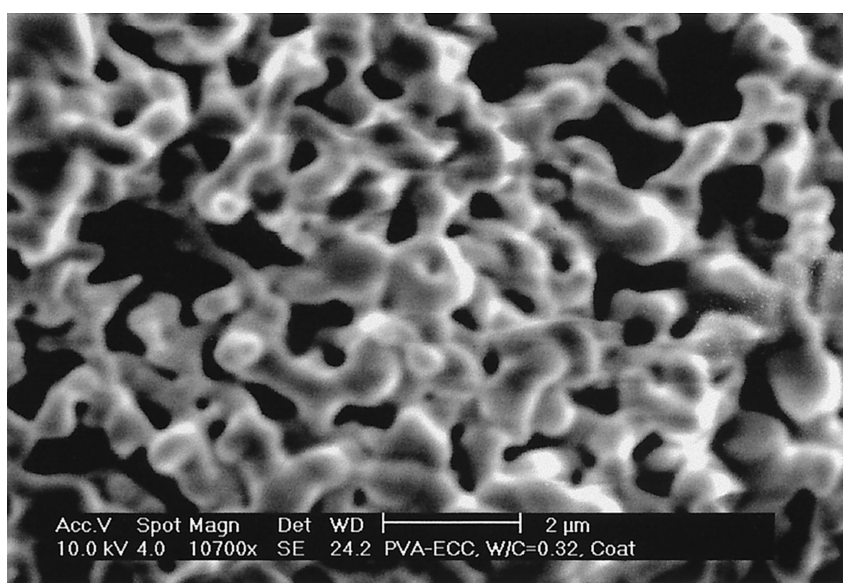

Fig. 2. SEM image of unreacted, as-received tantalum powder $(\mathrm{Ta}=$ $1.88 \mu \mathrm{m})$.

tantalum reactants will be distinguished by the manufacturer size specifications.

The Ta-C system was very sensitive to the presence or absence of a gas transport agent. Ignition of the samples could not be achieved without a minimum or critical mole fraction of gas transport agent present in the chamber $\left(\chi_{\mathrm{I}_{2}}>21 \%, \chi_{\mathrm{CO}_{2}}>41 \%\right)$. In addition, all samples exhibited delamination of the pellet structure as the combustion wave passed through the reactants. This delamination is consistent with a system where gas-phase reactions are significant ${ }^{14}$ and is discussed more below.

\section{(1) Microstructural Analysis}

The microstructure of the product materials was examined using both electron microscopy and nitrogen adsorption. Figure 3 is an SEM image of the tantalum carbide product for a condition of $\chi_{\mathrm{I}_{2}}=37.9 \%, P=0.26$ bar, and Ta $=1.88 \mu \mathrm{m}$. (The microstructure was generally uniform throughout each product specimen; hence, only images obtained at the center of the product specimens are shown.) Figure 4 is an SEM image of the TaC product for the same pressure and transport agent conditions as Fig. $3\left(\mathrm{I}_{2}=\right.$ $37.9 \%, P=0.26$ bar); however, the sample was obtained using the smaller tantalum reactant particles $(\mathrm{Ta}=1.14 \mu \mathrm{m})$. As seen by a comparison of Figs. 3 and 4, the product morphology is significantly influenced by the size of the initial tantalum powder particles. The product appears to have a morphology that is similar

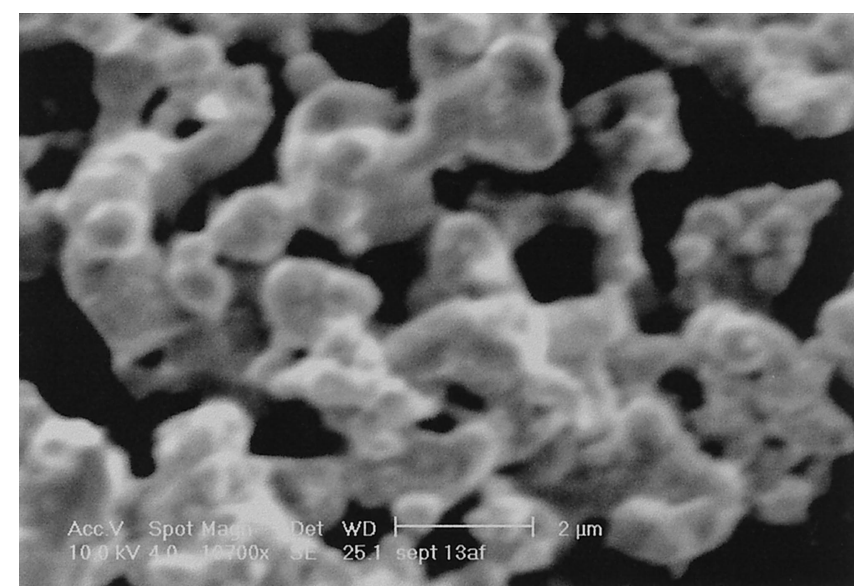

Fig. 3. SEM image of TaC product $\left(\mathrm{Ta}=1.88 \mu \mathrm{m}, \chi_{\mathrm{I}_{2}}=37.9 \%, P=\right.$ 0.26 bar).

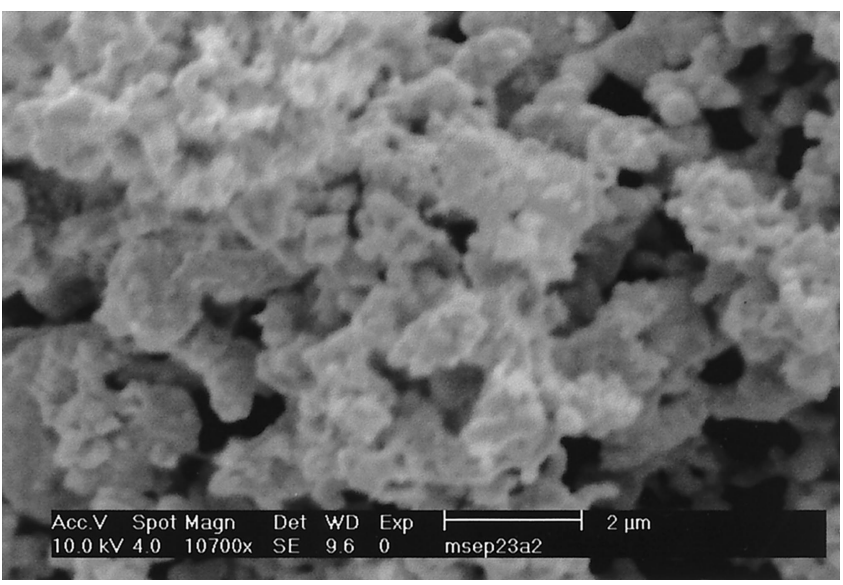

Fig. 4. SEM image of $\mathrm{TaC}$ product $\left(\mathrm{Ta}=1.14 \mu \mathrm{m}, \chi_{\mathrm{I}_{2}}=37.9 \%, P=\right.$ 0.26 bar).

in structure to the tantalum reactant. As a result, the $\mathrm{TaC}$ product formed from the $\mathrm{Ta}=1.14 \mu \mathrm{m}$ particles has smaller characteristic pore dimensions compared with the $\mathrm{TaC}$ product formed from the $\mathrm{Ta}=1.88 \mu \mathrm{m}$ particles. Throughout the range of conditions studied, the TaC microstructure observed via SEM imaging did not appear to vary significantly with iodine mole fraction and pressure, except as a function of the initial Ta particles used. SEM images of products obtained using $\mathrm{CO}_{2}$ as the transport agent exhibited the same trends; i.e., the type of tantalum reactant was the dominant factor affecting product morphology.

The results of the specific surface area (SSA) measurements are shown in Fig. 5 as a function of the mole fraction of gas transport agent in the vapor phase in the combustion chamber. Consistent with the SEM images, the specific surface areas of the materials produced using the smaller tantalum particles yielded higher specific surface areas. The specific surface areas for the $\mathrm{Ta}=$ $1.14 \mu \mathrm{m} / \mathrm{CO}_{2}$ and $\mathrm{Ta}=1.88 \mu \mathrm{m} / \mathrm{I}_{2}$ systems were both relatively 


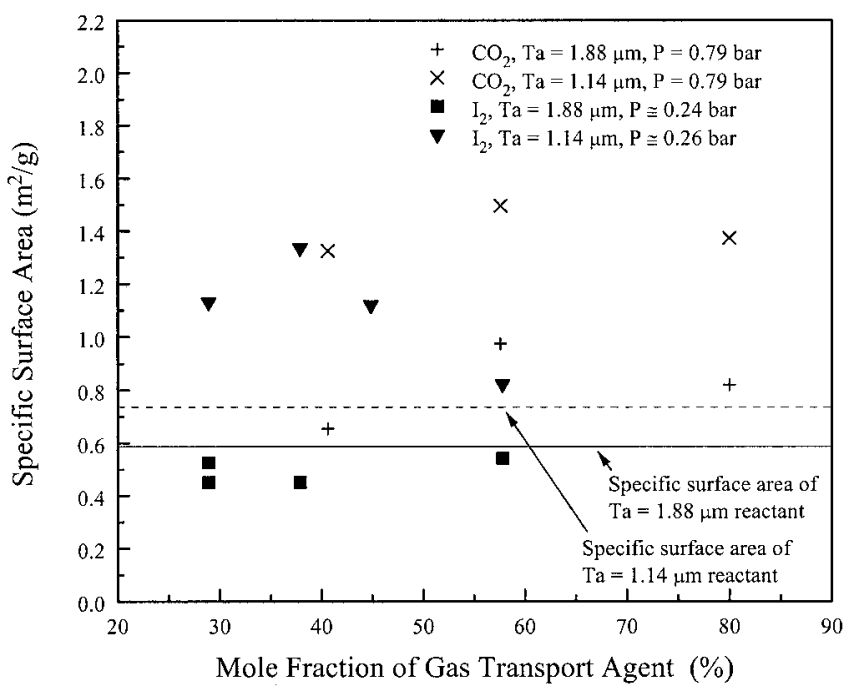

Fig. 5. Effect of gas transport agent on specific surface area as determined using BET.

insensitive to the concentration of transport agent present in the chamber. However, the specific surface areas were a strong function of pressure for all systems except the Ta $=1.88 \mu \mathrm{m} / \mathrm{I}_{2}$ system, as seen in Fig. 6. In fact, the specific surface area of the small Ta reactant $/ \mathrm{I}_{2}$ system increased by greater than a factor of 2 as pressure was decreased from 1.01 to 0.26 bar. Although the SEM images showed the product to have a morphology similar to that of the Ta reactant material, a comparison of specific surface areas shows that the SSAs of the TaC products were consistently higher than those of the corresponding Ta reactants for all cases and conditions studied except the Ta $=1.88 \mu \mathrm{m} / \mathrm{I}_{2}$ system (see Figs. 5 and 6). Note, data shown in Figs. 5 and 6 for identical experimental conditions (e.g., Ta $=1.88 \mu \mathrm{m}, P=0.24$ bar, and $\left.\chi_{\mathrm{I}_{2}}=28.9 \%\right)$ are results from separate experiments and indicate the repeatability of the study.

\section{(2) Compositional Analysis}

Product composition was investigated using X-ray diffraction. The composition of $\mathrm{TaC}$ was validated by comparison with the $\mathrm{TaC}$ diffraction pattern standard provided by the Joint Committee for Powder Diffraction Standards (JCPDS) and XRD results of Larson and co-workers, ${ }^{15}$ who also studied SHS synthesis of TaC. A typical XRD trace is shown in Fig. 7. All of the product samples indexed to tantalum carbide with no indication of the presence of

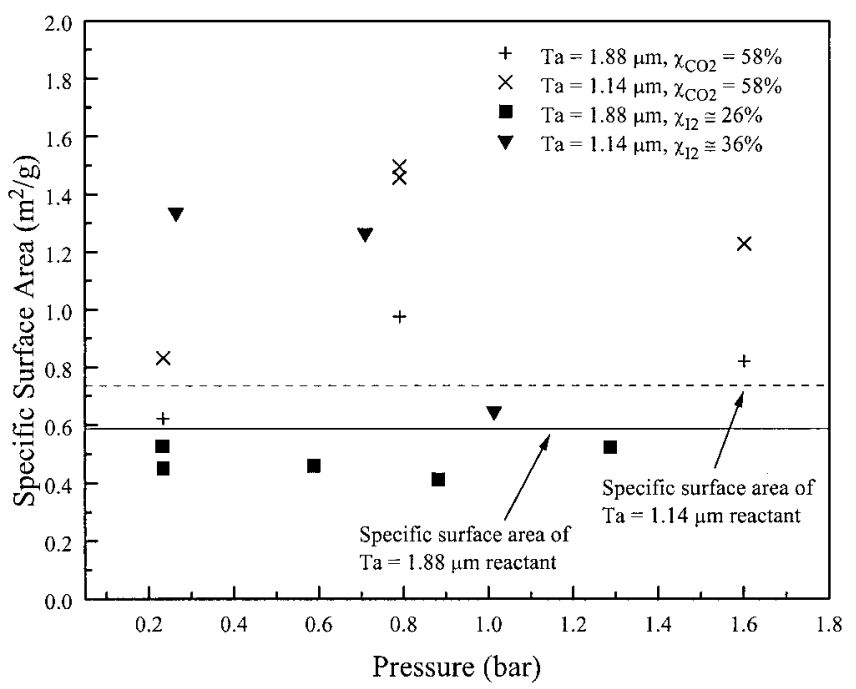

Fig. 6. Effect of pressure on specific surface area as determined using BET.

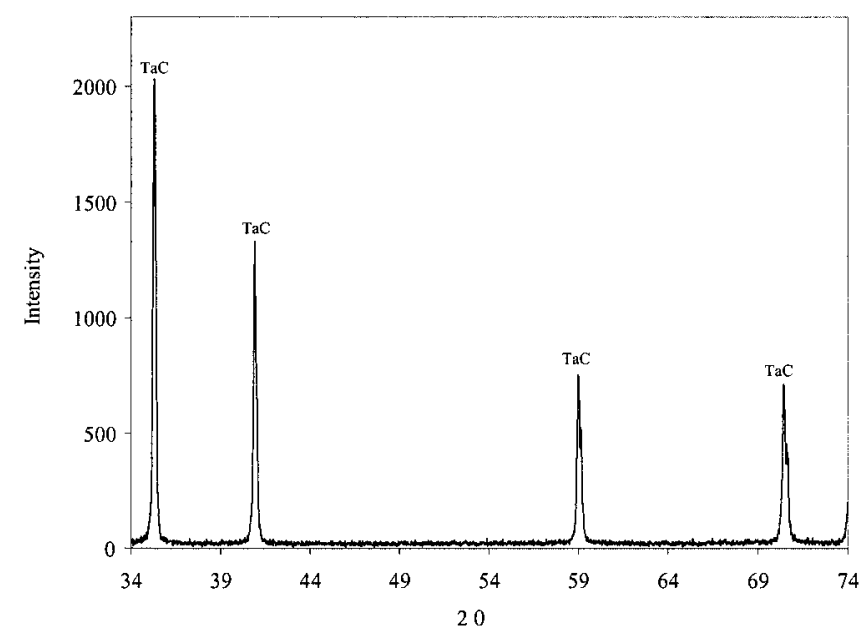

Fig. 7. Typical XRD trace $\left(\mathrm{Ta}=1.14 \mu \mathrm{m}, \chi_{\mathrm{I}_{2}}=37.9 \%, P=0.26\right.$ bar $)$.

impurities such as tantalum subcarbide $\left(\mathrm{Ta}_{2} \mathrm{C}\right.$, an intermediate species in the $\mathrm{Ta} / \mathrm{C}$ system $),{ }^{1,2}$ unreacted tantalum, or any oxide or iodine species. Unreacted carbon black would not appear in the XRD analysis due to the amorphous structure. If $\mathrm{Ta}_{2} \mathrm{C}$ or Ta were present, peaks should be observed at $2 \theta \cong 36.5^{\circ}, 38^{\circ}, 72^{\circ}$ for $\mathrm{Ta}_{2} \mathrm{C}$ and $2 \theta \cong 38.5^{\circ}, 56^{\circ}, 69.5^{\circ}$ for $\mathrm{Ta}^{15}$

$\mathrm{TaC}$ can exist in a range of stoichiometries (i.e., C:Ta ratios). ${ }^{16}$ Therefore, the $2 \theta \cong 128^{\circ}$ peak locations from the XRD spectra were used to determine $\mathrm{TaC}$ lattice parameters using the relation ${ }^{17}$

$$
\sin ^{2} \theta=\left(\frac{\lambda^{2}}{4 a^{2}}\right)\left(h^{2}+k^{2}+l^{2}\right)
$$

where $\lambda$ is the X-ray wavelength (1.5406 $\AA$ ), $a$ is the lattice parameter, $\theta$ is the peak diffraction angle, and the Miller indices corresponding to the peak angle $2 \theta=127.87^{\circ}(h, k, l)$ are $(5,1,1){ }^{16}$ The lattice parameters were in turn used to determine the corresponding molar ratios via the relationship given by Storms ${ }^{16}$

$$
\frac{\mathrm{C}}{\mathrm{Ta}}( \pm 0.01)=-25.41+5.9757 a
$$

Figure 8 shows the results for product composition as a function of the mole fraction of transport agent in the chamber. In general, the $\mathrm{TaC}$ formed by $\mathrm{CO}_{2}$-assisted $\mathrm{SHS}$ yielded lower C:Ta stoichiometries than $\mathrm{TaC}$ formed by $\mathrm{I}_{2}$-assisted SHS. Although the stoichiometries for the $\mathrm{I}_{2}$ samples were a weak function of $\mathrm{I}_{2}$ mole fraction, the $\mathrm{CO}_{2}$ samples exhibited marked dependence on the

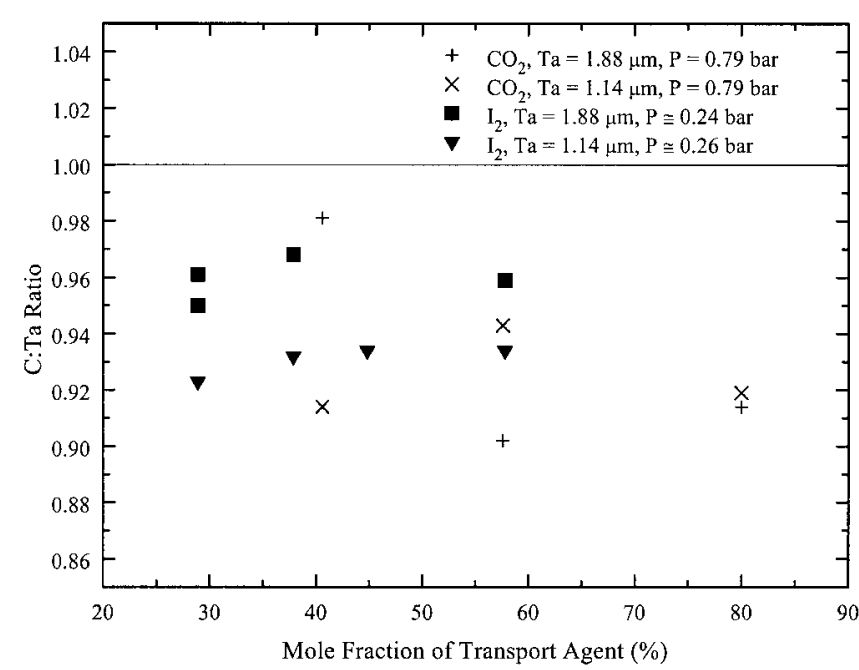

Fig. 8. Effect of gas transport agent on tantalum carbide stoichiometries as determined using XRD. 
$\mathrm{CO}_{2}$ mole fractions. Pressure effects on the product composition were negligible for all conditions, as seen in Fig. 9. Again, please note that data shown in Figs. 8 and 9 for identical experimental conditions are results from separate experiments.

\section{Discussion}

The effects of pressure, tantalum particle size, and gas transport agent are consistent with what little is known regarding the transport mechanisms important to the $\mathrm{I}_{2} / \mathrm{Ta} / \mathrm{C}$ and $\mathrm{CO}_{2} / \mathrm{Ta} / \mathrm{C}$ systems. Figures 10 and 11 are schematics representing possible physical mechanisms for the transport via $\mathrm{I}_{2}$ and $\mathrm{CO}_{2}$, respectively. Both figures include portions that represent the conversion of tantalum and carbon to tantalum carbide via the solid diffusion model proposed by Xue and Munir. ${ }^{10}$ The solid diffusion mechanism consists of carbon diffusion into the tantalum matrix, which results in a TaC layer encapsulating a tantalum core. Subsequent conversion to $\mathrm{TaC}$ occurs via diffusion of the carbon through the $\mathrm{TaC}$ layer. Xue and Munir proposed that the carbon diffusion through the $\mathrm{TaC}$ layer is the rate-limiting step in the conversion process. The authors also identified tantalum subcarbide $\left(\mathrm{Ta}_{2} \mathrm{C}\right)$ as an intermediate formed in the system; however, conversion to $\mathrm{TaC}$ occurred rapidly.

In gas-assisted SHS systems both solid-phase diffusion transport and gas-phase diffusion transport are present. The transport of metals by halogen species is well known. ${ }^{18-21}$ Figure 10 includes the cycle proposed by Jeffes and Marples, ${ }^{18}$ where $\mathrm{TaI}_{5}$ is produced via $\mathrm{Ta}(\mathrm{s})+2 \frac{1}{2} \mathrm{I}_{2}(g) \rightarrow \mathrm{TaI}_{5}(g)$ at low temperatures, and then tantalum is condensed by the reverse reaction at high temperatures. Note that because the iodine transport system is thermally driven, iodine cannot be reused to transport tantalum multiple times. Once the sample reaches the elevated combustion temperatures, $\mathrm{TaI}_{5}$ will not be formed in significant quantities. In the catalytically assisted $\mathrm{I}_{2} / \mathrm{Ta} / \mathrm{C}$ SHS system, the reaction with $\mathrm{I}_{2}$ physically transports tantalum to the carbon particles, thereby enhancing the overall efficiency of the conversion to tantalum carbide products. The increased transport efficiency results in higher C:Ta ratios compared with unassisted SHS systems (e.g., Shkiro and co-workers obtained C:Ta $<0.90$ for all conditions examined in their studies of the unassisted $\mathrm{Ta} / \mathrm{C}$ system $)^{14,24}$ and compared with the $\mathrm{CO}_{2}$-assisted system. In addition, the iodine transport breaks the tantalum particles into smaller components, which should result in higher specific surface areas than if carbon simply diffused into the existing tantalum particles. Figures 5 and 6 show this is the case for all conditions studied (including the $\mathrm{CO}_{2}$-assisted samples) except the $\mathrm{I}_{2} / \mathrm{Ta}=1.88 \mu \mathrm{m}$ system. This exception is likely due to the size of the tantalum particles and the resulting packing density, which is discussed further below.

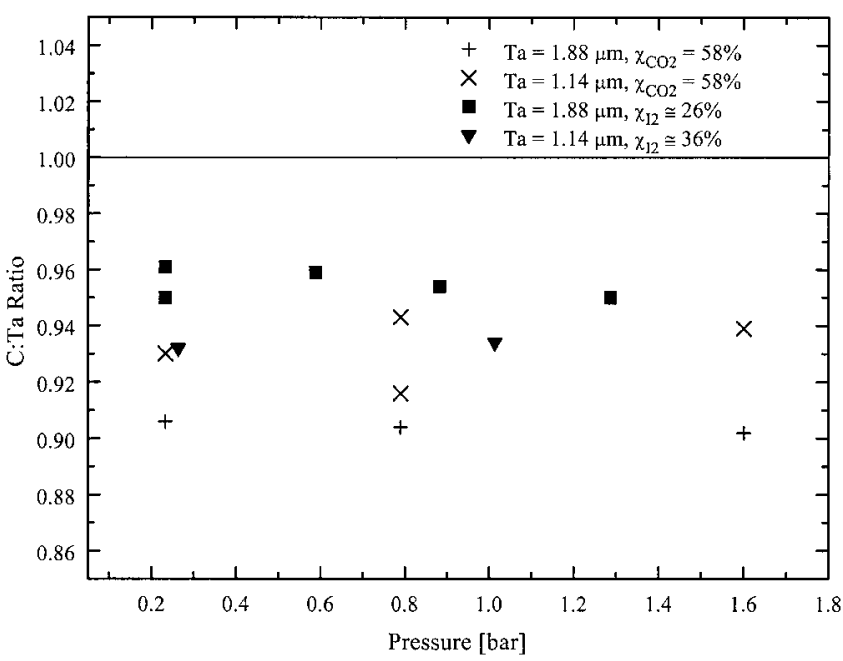

Fig. 9. Effect of pressure on tantalum carbide stoichiometries as determined using XRD.

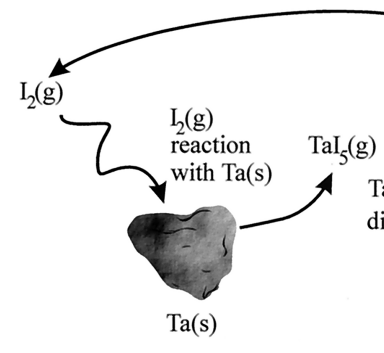

a) Low temperatures
$(\mathrm{T}<\sim 1100 \mathrm{~K})$

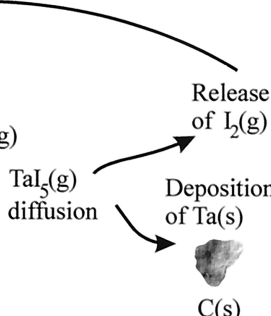

C diffusion

b) High temperatures

$(\mathrm{T}>\sim 1400 \mathrm{~K})$ into Ta lattice $\mathrm{TaC}(\mathrm{s})$

Fig. 10. Schematic of proposed transport mechanisms in the $I_{2} / \mathrm{Ta} / \mathrm{C}$ system.

The $\mathrm{CO}_{2} / \mathrm{Ta} / \mathrm{C}$ transport system is more complicated than the iodine system, involving multiple steps and chemical reactions as seen in Fig. 11. The gas-phase transport mechanism shown in the figure is primarily based on the transport steps proposed by Merzhanov et al. ${ }^{6}$ in their study of the effects of $\mathrm{O}_{2}$ impurities on the $\mathrm{Ta} / \mathrm{C}$ SHS system. For the $\mathrm{CO}_{2}$ system studied in the current work, the transport mechanism is initiated by conversion of the $\mathrm{CO}_{2}$ to $\mathrm{CO}$ via the Boudoir reaction $\mathrm{CO}_{2}(g)+\mathrm{C}(s) \rightarrow 2 \mathrm{CO}(g)$. This reaction is rapid at combustion temperatures $(<115 \mu \mathrm{s}, T=$ $2700 \mathrm{~K})^{22}$ and proceeds to virtually complete conversion $\left(K_{\mathrm{p}}=\right.$ $\left.7 \times 10^{4} \mathrm{MPa}, T=2700 \mathrm{~K}\right){ }^{6}{ }^{6}$ The carbon monoxide formed diffuses rapidly at high temperatures for small interparticle distances $(<1 \mu \mathrm{s}$ for distances $\sim 5 \mu \mathrm{m}, T=2700 \mathrm{~K}) .{ }^{6}$ The carbon monoxide is adsorbed onto the surface of the tantalum particles where reaction to form $\mathrm{TaC}(s)$ and release of the adsorbed oxygen then proceed. The oxygen reacts with carbon monoxide to form carbon dioxide, which completes the catalyst cycle. Gas-phase tantalum oxides $\left(\mathrm{TaO}, \mathrm{TaO}_{2}, \mathrm{Ta}_{2} \mathrm{O}_{5}\right)$ can also form in the system; however, equilibrium calculations indicate orders of magnitude lower concentrations compared with $\mathrm{CO}$ and $\mathrm{CO}_{2}{ }^{6}$ In the catalytically assisted $\mathrm{Ta} / \mathrm{C}$ SHS system, the reaction with $\mathrm{CO}_{2}$ physically transports carbon to the tantalum particles. Unlike the $\mathrm{I}_{2}$ system, the $\mathrm{CO}_{2}$ system is not a thermal cycle and therefore the $\mathrm{CO}_{2}$ can be recycled to repeatedly transport carbon particles. Again, the presence of the transport agent enhances the conversion of reactants to products and results in higher tantalum carbide stoichiometries, although $\mathrm{CO}_{2}$ is not as effective as iodine for most conditions. It is also interesting to note that although the $\mathrm{CO}_{2}$ system transports carbon, there is still an increase in the specific surface area of the $\mathrm{TaC}$ product over that due to the tantalum reactant alone.

Merzhanov et al. ${ }^{6}$ proposed that the $\mathrm{CO}$ adsorption onto the surface of the tantalum particle step is the rate-limiting step in the $\mathrm{CO}_{2}$ transport mechanism. Physical observations of the products in the current study support that conclusion. Many of the $\mathrm{TaC}$ products resulting from the $\mathrm{CO}_{2}$-assisted SHS were distinguished by thin black layers along the interior surfaces of pores in the samples. The composition of the layers could not be identified; however, amorphous carbon would not appear on XRD scans. If the carbon adsorption and reaction process is rate limiting, the result could be thin carbon layers on the pore surfaces. Note that unreacted carbon may lead to overestimates of the specific surface area attributable to tantalum carbide (by $\sim 20 \%$ ) for the systems with low conversion efficiencies, i.e., C:Ta ratios $<0.92$. These black layers were not observed in the interior of the $\mathrm{I}_{2}$-assisted products.

Particle size effects in catalytically assisted SHS are due to the surface contact area between particles and the corresponding void fraction in the sample. In combustion synthesis systems where gas transport is minimal, smaller reactant particles generally lead to increased contact area between reactants and therefore higher reaction rates. ${ }^{2}$ In the current study, because the packing pressure was fixed for both the large and the small tantalum reactants, the specimens made from the $\mathrm{Ta}=1.14 \mu \mathrm{m}$ particles had larger void fractions with less contact area between particles. Gas-phase transport should play a more critical role in these systems and the 


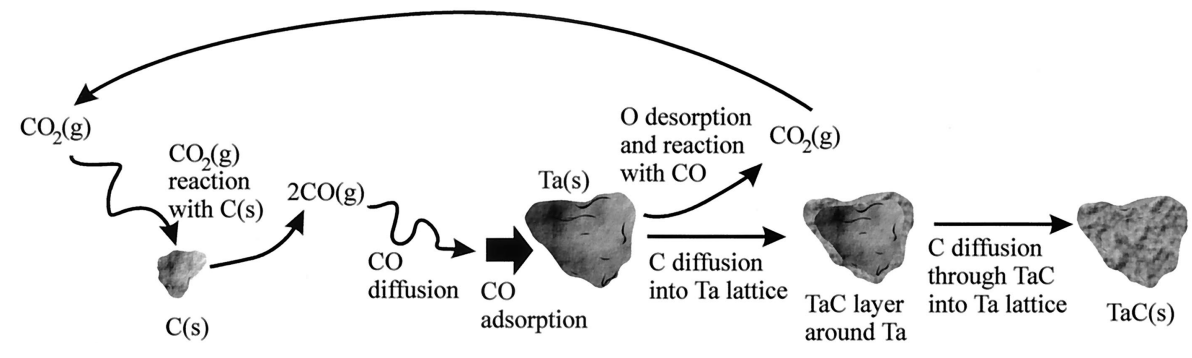

Fig. 11. Schematic of proposed transport mechanisms in the $\mathrm{CO}_{2} / \mathrm{Ta} / \mathrm{C}$ system.

$\mathrm{Ta}=1.14 \mu \mathrm{m}$ samples should be more responsive to changes in the gas-phase transport conditions. Indeed, the microstructure of the products of the smaller tantalum reactant systems showed greater sensitivity to the pressure and gas transport agent concentrations for both $\mathrm{CO}_{2}$ and $\mathrm{I}_{2}$.

In addition, the results from the iodine experiments indicate that a critical pore size (or combination of particle size and packing density) may exist for the iodine-assisted SHS system (see Figs. 5 and 8), with different transport mechanisms limiting the conversion process for systems above or below this critical pore size. Gas-phase transport is critical to sustain reaction in all of the iodine systems studied. However, in iodine systems with pore sizes below the critical pore size (or conversely with high particle surface contact areas), gas-phase transport is more rapid and solid diffusion may become the limiting transport process. Hence, the higher $\mathrm{C}$ :Ta ratios observed for the $\mathrm{Ta}=1.88 \mu \mathrm{m}$ iodine materials.

The effect of pressure on product composition was minimal; however, the effect on product microstructure was significant for certain conditions. Changes in pressure or mole fraction will shift equilibrium reactions, augmenting or detracting from the net gas-phase transport processes. For example, for a given temperature, an increase in pressure will shift the $\mathrm{Ta}(s)+2 \frac{1}{2} \mathrm{I}_{2}(g) \leftrightarrow$ $\mathrm{TaI}_{5}(g)$ reaction to form more $\mathrm{TaI}_{5}$, thus enhancing the tantalum transport. However, pressure also affects the microstructure by the release of gas-phase species from the particle surfaces. The formation of gas-phase species within the pores of the specimens can lead to localized regions of very high pressures, ${ }^{6,23}$ which in turn cause delamination of the specimen. The net result is an increase in the specific surface area of the product due to both the gas-phase transport and the fragmentation processes. The effects of pressure on specific surface area followed trends similar to those observed with respect to mole fraction of transport agent (where pressure was held constant). Consequently, the implication is that the gas-phase transport processes dominate compared with fragmentation in affecting the microstructure of the final product.

The conditions leading to maximum specific surface area are system specific as indicated by the results of the current work and are a complex function of the transport processes (i.e., surface reactions, adsorption rates, etc.). Because the pressure did not significantly affect the product composition, pressure may be used to control product microstructure with minimal impact on the final product stoichiometry. On the other hand, the product stoichiometry can be optimized using reactant particle size and the gastransport agent conditions.

There have been few efforts to model gas-phase transport in SHS systems. Kostogorov and Dorozhevets ${ }^{4}$ have developed a simplified single-cell model. Similarly, Shtessel and Dorozhevets ${ }^{5}$ used a simplified two-layer approach to model the gas-assisted SHS system. However, both studies primarily focused on determination of burning velocities and did not address pressure effects, multistep reactions, or adsorption and desorption. As a result, there are no existing modeling data available for comparison with the present experimental study.

\section{Conclusions}

The current work represents the first investigation of the intentional use of gas-phase transport agents in Ta/C SHS studies for the purpose of affecting product microstructure and composition. In comparison to unassisted SHS studies of the Ta/C system (where conversion efficiencies were less than $90 \%$ throughout the range of conditions studied), ${ }^{14,24}$ the conversion efficiencies obtained in the current work are considerably improved. In particular, no oxide impurities were observed when an oxygen-containing transport agent was used. In addition, parameters affecting the morphology of the gas-assisted SHS TaC product were isolated (e.g., reactant particle size, system pressure and the concentration of transport agent present).

Catalytically assisted SHS appears to be a very promising method for synthesis of materials with controlled microstructure and composition. The reactant conditions (particle size and mole fraction of transport agent) can be selected in conjunction with the pressure in the combustion chamber to yield a product optimized for high specific surface areas and high conversion efficiencies. Although the specific surface areas obtained in the current work are not yet competitive with other synthesis methods (such as temperature-programmed reaction synthesis), which can produce metal carbides with specific surface areas on the order of $50-$ $100 \mathrm{~m}^{2} / \mathrm{g}$, the catalytically assisted SHS process has not been optimized for these target values. In particular, the results of the present study suggest that the use of nanostructured reactants (i.e., more porous or smaller tantalum particles) will lead to nanostructured products.

\section{Acknowledgments}

We would like to sincerely thank Anne Wang for her assistance with the SEM, BET, and XRD analyses, and Srinidhi Nagaraja and Michael Keinath for their assistance with the BET analysis.

\section{References}

${ }^{1}$ A. G. Merzhanov, "Solid Flames: Discoveries, Concepts, and Horizons of Cognition," Combust. Sci. Technol., 98, 307-36 (1994).

${ }^{2} Z$. A. Munir and U. Anselmi-Tamburini, "Self-Propagating Exothermic Reactions: The Synthesis of High-Temperature Materials by Combustion," Mater. Sci. Rep., 3, 277-365 (1989).

${ }^{3}$ K. Brezinsky, "Gas-Phase Combustion Synthesis of Materials"; pp. 1805-16 in Proceedings of the 26th International Symposium on Combustion. The Combustion Institute, Pittsburgh, PA, 1996.

${ }^{4}$ E. P. Kostogorov and I. N. Dorozhevets, "Transport Reactions in SHS Combustion," Int. J. Self-Propag. High-Temp. Synth., 1, 33-39 (1992).

${ }^{5}$ E. A. Shtessel and I. N. Dorozhevets, "Combustion of Heterogeneous Condensed Systems in the Presence of Chemical Transport Reactions," Combust., Explos. Shock Waves (Engl. Transl.), 26, 52-59 (1990).

${ }^{6}$ A. G. Merzhanov, A. S. Rogachev, A. S. Mukas'yan, B. M. Khusid, I. P Borovinskaya, and B. B. Khina, "The Role of Gas-Phase Transport in Combustion of the Tantalum-Carbon System," J. Eng. Phys., 59, 809-16 (1991).

${ }^{7}$ D. C. Halverson, K. H. Ewald, and Z. A. Munir, "Improving the Uniformity in Combustion-Synthesized Titanium Carbide," J. Mater. Sci., 30, 3697-703 (1995).

${ }^{8}$ O. E. Kashireninov, I. A. Yuranov, and A. A. Fomin, "High-Temperature Thermochemistry of Gas-Phase Transport in Solid State Combustion of SHS Systems"; pp. 1899-906 in Proceedings of the 24th International Symposium on Combustion. The Combustion Institute, Pittsburgh, PA, 1992.

${ }^{9} \mathrm{~S}$. T. Oyama, "Preparation and Catalytic Properties of Transition Metal Carbides and Nitrides," Catal. Today, 15, 179-200 (1992).

${ }^{10} \mathrm{H}$. Xue and Z. A. Munir, "Field-Activated Combustion Synthesis of TaC," Int. J. Self-Propag. High-Temp. Synth., 5, 229-37 (1996).

${ }^{11}$ T. Kim and M. S. Wooldridge, "Burning Velocities in Catalytically Assisted Self-Propagating High-Temperature Combustion Synthesis Systems," Combust. Flame, in press.

${ }^{12} \mathrm{~A}$. Makino and C. K. Law, "SHS Combustion Characteristics of Several Ceramics and Intermetallic Compounds," J. Am. Ceram. Soc., 77, 778-786 (1994). 
${ }^{13}$ V. A. Knyazik and A. S. Shteinberg, "High-Temperature Interaction in the Ta-C System Under Electrothermal Explosion Conditions," J. Mater. Synth. Process., 1, 85-92 (1993).

${ }^{14}$ V. M. Shkiro, G. A. Nersisyan, and I. P. Borovinskaya, "Principles of Combustion of Tantalum-Carbon Mixtures," Combust., Explos. Shock Waves (Engl. Transl.), 14, 58-64 (1978).

${ }^{15}$ E. M. Larson, J. Wong, J. B. Holt, P. A. Waide, G. Nutt, B. Rupp, and L. J. Terminello, "Time-Resolved Diffraction Study of Ta-C Solid Combustion System," J. Mater. Res., 8, 1533-41 (1993).

${ }^{16} \mathrm{E}$. Storms, Refractory Carbides. Academic Press, New York, 1967.

${ }^{17}$ C. Suryanarayana and M. G. Norton, X-Ray Diffraction: A Practical Approach. Plenum Press, New York, 1998.

${ }^{18}$ J. H. E. Jeffes and T. N. R. Marples, "The Thermodynamics of Chemical Transport Reactions with Special References to the Transport of Tantalum by Iodine," J. Cryst. Growth, 17, 46-52 (1972).
${ }^{19}$ B. Armas, J. H. E. Jeffes, and M. G. Hocking, "The Vapour Transport of $\mathrm{NbB}_{2}$ and $\mathrm{TaB}_{2}, "$ J. Cryst. Growth, 44, 609-12 (1978).

${ }^{20}$ J. J. Murray, J. B. Taylor, and L. Usner, "Halogen Transport of Molybdenum Arsenides and Other Transition Metal Pnictides," J. Cryst. Growth, 15, 231-39 (1972).

${ }^{21}$ H. Oppermann, "The Role of Halogens, Halogenides, Oxide Halogenides and Their Complexes in Chemical Transport Reactions," Solid State Ionics, 39, 17-25 (1990).

${ }^{22}$ D. L. Smoot and P. J. Smith, Coal Combustion and Gasification. Plenum Press, New York, 1985.

${ }^{23}$ R. Jackson, Transport in Porous Catalysts. Elsevier, New York, 1977.

${ }^{24}$ V. M. Shkiro, G. A. Nersisyan, I. P. Borovinskaya, A. G. Merzhanov, and V. Sh. Shekhtman, "Preparation of Tantalum Carbides by Self-Propagating HighTemperature Synthesis," Sov. Powder Metall. Met. Ceram. (Engl. Transl.), 18, 227-30 (1979). 